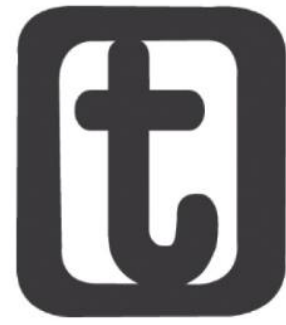

\section{PROTEÇÃO SOCIAL E PANDEMIA DA COVID-19: O LUGAR DA TRANSFERÊNCIA DE RENDA}

\author{
Social protection and pandemic of COVID-19: the place of income transfer
}

\author{
Almira Almeida Cavalcante* \\ https://orcid.org/0000-0002-8703-6107
}

\section{RESUMO}

O presente artigo reflete sobre os impactos sofridos pelo Sistema de Proteção Social no Brasil no processo de crise da pandemia da COVID-19. A compreensão de proteção social está pautada na política de assistência social, assegurada pelo Sistema Único de Assistência Social (SUAS). Enfatizamos a segurança de renda afiançada na proteção social básica do SUAS, a partir do Programa de Transferência Condicionada de Renda Bolsa Família (PBF). Objetivamos analisar os efeitos da crise causada pela pandemia, em termos de desvelar as fragilidades da proteção social. Trata-se de um estudo exploratório de abordagem qualitativa, realizado a partir da análise de recentes publicações, bem como do estudo de legislações e consulta de base de dados dos órgãos governamentais que monitoram o processo da pandemia e suas consequências. Embora os documentos pesquisados sobre a pandemia apresentem limitação de dados, ante a dinâmica a qual foi exposta a sociedade e por conseguinte o Sistema de Proteção Social, em decorrência dessa discussão podemos apontar que: a transferência de renda efetivada no SUAS pelo PBF há quase 17 anos corresponde a um mecanismo de proteção social notoriamente insatisfatório; o modelo de definição orçamentária do programa que não se enquadra na prerrogativa do direito sinaliza a desproteção do Estado à população mais vulnerável; a negligência ante o princípio da universalidade outorga a continuidade da desigualdade e negativa de direitos; os valores conferidos ao corte de renda pressupõem a estagnação da pobreza e da extrema pobreza da população.

\section{PALAVRAS-CHAVE}

Proteção Social. Bolsa Família. Sistema Único de Assistência Social.

\section{ABSTRACT}

This article reflects on the impacts suffered by the Protection System in Brazil in COVID-19 pandemic crisis process. The understanding of social protection is based on the social assistance policy, ensured by the Unified Social Assistance System (SUAS). We emphasize the security of guaranteed income in basic social protection of SUAS, through the Bolsa Família Conditional Income Transfer Program (PBF). We aim to analyze the effects of the crisis caused by the pandemic, in terms of unveiling the weaknesses of social protection. This is an exploratory study with a qualitative approach, carried out based on the analysis of recent

\footnotetext{
* Assistente Social. Mestre em Serviço Social. Doutoranda em Estudos Urbanos e Regionais - Gestão de Políticas Públicas - no Programa de Pós-Graduação em Estudos Urbanos e Regionais do Departamento de Políticas Públicas da Universidade Federal do Rio Grande do Norte (UFRN, Natal, Brasil). Centro de Convivência - 59078 970, Av. Sen. Salgado Filho, 3000, Sala 9, S/N, Lagoa Nova, Natal (RN), CEP.: 59064-720. Assistente Social da Secretaria de Educação do Município de João Pessoa (PMJP). E-mail: almiracavalcante@hotmail.com.
}

DOI 10.22422/temporalis.2021v21n41p205-218 material em qualquer suporte ou formato, bem como adaptar, transformar e criar a partir deste material para qualquer fim, mesmo que comercial. O licenciante não pode revogar estes direitos desde que você respeite os termos da licença. 
publications, as well as the study of legislation and consultation of the database of government agencies that monitor the pandemic process and its consequences. Although the researched documents about the pandemic present data limitations, in view of the dynamics to which society was exposed and, consequently, the Social Protection System, as a result of this discussion we can point out that: the transfer of income effected in SUAS by PBF almost 17 years ago corresponds a notoriously unsatisfactory social protection mechanism; the model of budget definition of the program that does not fit the prerogative of the right signals the lack of protection of the State to the most vulnerable population; neglect in face of the principle of universality grants continuity of inequality and denial of rights; the values attached to the income cut presuppose the stagnation of poverty and the extreme poverty of the population.

\section{KEYWORDS}

Social Protection. Bolsa Família. Unified Social Assistance System.

Submissão: 22/3/2021.

Aceito em: 11/6/2021.

\section{INTRODUÇÃO}

$\mathrm{O}$ $\mathrm{s}$ apontamentos apresentados neste artigo, elaborado no primeiro semestre do ano de 2020, há aproximadamente dois meses após a emergência da pandemia da COVID-19 preanunciam que os impactos sofridos pelo sistema de proteção social requisitam novas posturas da pesquisa científica em diversas áreas do conhecimento; enquanto cientistas da área de saúde se esforçam conjuntamente na busca da vacina que detenha a proliferação do vírus e em medicamentos que apresentem eficácia na minimização dos sintomas e letalidade, com vistas a preservar a vida da população no mundo, as áreas do conhecimento econômico, social e político são alertadas para investigar como e em que condições a população não infectada, ou infectada e poupada da letalidade do vírus, viverá na pós-crise pandêmica considerando que o cenário que se aproxima será seguido de crises: social, econômica e, em alguns aspectos, política. Em outras palavras, compete aos pesquisadores analisar o pós-crise que vem sendo desvelado neste momento pelo agravamento da crise sanitária.

A segunda década deste século foi invadida pelo fenômeno da pandemia da COVID-19, doença causada pelo novo corona vírus SARS-Cov-2. Trata-se de uma nova infecção aguda com potencial para alcançar proporções pandêmicas em breve espaço de tempo. De acordo com o Pandemic Severity Assessment Framework -PSAF (Quadro de Avaliação de Gravidade Pandêmica), elaborado pelo Department of Health and Human Services (Departamento de Saúde e Serviços Humanos) dos Estados Unidos, a COVID-19 associa-se a outras epidemias severas presentes na história, como por exemplo a influenza de 1918 (FREITAS; NAPIMOGA; DONALÍSIO, 2020). Outrossim, os estudos desenvolvidos, bem como a realidade, alertam para fatores como: alta transmissibilidade, gravidade clínica e índice de letalidade, sendo que este último pode ser afetado por aspectos como: conhecimento da doença, capacidade diagnóstica instalada e superlotação hospitalar (FREITAS; NAPIMOGA; DONALÍSIO, 2020).

O elemento letalidade também está relacionado a faixa etária e sexo, atingindo homens com mais de 50 anos e idosos em geral, acrescido da presença de comorbidades na pessoa infectada pelo vírus (CHEN, et all, 2020, apud MACEDO; ORNELAS; BOMFIM, 2020). Inicialmente é visto que o cenário da pandemia demanda iniciativas urgentes das autoridades sanitárias quanto ao esforço para o controle da doença. Poderíamos classificar o SARS-Cov-2 ou Novo Corona Vírus, como também vem sendo chamado, como um vírus impessoal, pois é sabido pela comunidade científica e comprovado pela realidade que se 
trata de um vírus capaz de causar uma pandemia, fato em curso decretado pela Organização Mundial de Saúde (OMS) em 11 de março de 2020.

De acordo com a etimologia “[...] a palavra pandemia tem sua origem no grego pandemías, as; pela junção de pan que significa todo + demos com o sentido de povo + ia" (DICIONÁRIO ONLINE DE PORTUGUÊS, 2020). Em outras palavras, trata-se de um fenômeno capaz de atingir populações de uma região inteira, nações, continentes, mundo. Diante do espraiamento mundial podemos asseverar que o SARS-Cov-2 é um elemento globalizado.

No primeiro momento, o SARS-Cov-2 parece não eleger raça, etnia, família, cor, cultura, ou classe social. Considerando, contudo, que a população mais pobre do Brasil é composta por pessoas negras (PASSOS, 2020), no segundo momento percebe-se que a contaminação para esse estrato social mostra-se cada vez mais acentuada. Assim o SARS-Cov-2 apresenta também características pessoais em termos de possuir histórico familiar, local e data de nascimento. É oriundo das famílias dos corona vírus humanos, denominados de corona em 1965 devido a sua aparência com uma coroa.

O SARS-Cov-2 foi descoberto em Whan em 31 de dezembro de 2019. O caráter pessoal do causador da COVID-19 não se encerra nos dados pessoais, a manifestação da doença revela que à medida que há condições propícias para o contágio acentua-se também a dimensão relacional do vírus, visto que o maior número de infectados traz consigo especificidades de: classe social, cor, raça, etnia, gênero, nacionalidade, cultura, dentre outros elementos que passam a caracterizar o lugar de evidência do vírus e consequentemente da pandemia da COVID-19 por ele causada.

Assinalamos que a característica do vírus só tem razão de ser devido às desigualdades que se estabelecem nos elementos intrínsecos nas relações sociais (classe social, cor, raça, etnia, gênero, nacionalidade, cultura, entre outros) e na alta incidência de contaminação e letalidade nos diversos territórios invadidos pelo vírus.

A análise sobrescrita do Novo Corona Vírus remete aos espaços propícios ao espraiamento e implicações no enfrentamento da doença, em termos de prevenção da contaminação. Alguns cientistas que vêm se debruçando sobre o fenômeno da pandemia afirmam que "[...] O SARS-CoV-2 é um vírus respiratório diferente do vírus da influenza, cujo comportamento ainda não foi totalmente esclarecido [...]" (FREITAS; NAPIMOGA; DONALísIO, 2020, p. 4), portanto não há consenso sobre a tomada de decisão mais eficaz. O que tem ficado claro é que a pandemia é causadora de uma crise sanitária de proporção exponencial em contexto internacional.

Ademais o fator mais inquietante é não haver a curto ou médio prazo mecanismo de contenção do espraiamento do vírus. "Teoricamente no dia um há uma pessoa infectada, no dia seguinte são duas pessoas. No terceiro dia serão quatro infectados. No quarto dia oito infectados e assim seletivamente. No décimo quinto dia haverá 16.384 infectados" (MACEDO; ORNELAS; BOMFIM, 2020, p. 3). A progressão geométrica citada denuncia a forma avassaladora que o vírus se propaga.

A ausência de vacina para a população, ou tratamento no combate à doença, vêm assegurar às autoridades sanitárias do mundo o isolamento social como medida de

Temporalis, Brasília (DF), ano 21, n. 41, p. 205-218, jan./jun. 2021. | ISSN 2238-1856 
prevenção mais eficiente, sendo mais eficaz o isolamento dito horizontal na maioria dos países. Assim o isolamento social surge como único mecanismo imediato de evitar o contágio da doença, além das medidas de higiene (lavar as mãos e fazer uso de álcool gel 70\%) imediatamente após possível contato com pessoa ou ambiente contaminado pelo vírus, bem como o uso de máscaras de proteção a fim de evitar o compartilhamento de gotículas contaminadas (ORGANIZAÇÃO MUNDIAL DE SAÚDE, 2020).

Medida como testagem em massa também contribui com a minimização da doença, tendo em vista que os positivamente infectados podem ser isolados e o tratamento iniciado antes do desenvolvimento dos sintomas para um quadro grave. No entanto, esse tipo de precaução não será alcançado pela maioria dos países do mundo, seja devido às condições econômicas, seja devido à falta de testes disponíveis no setor de comercialização desses insumos, déficit na produção, transporte e logística causados pela pandemia.

O isolamento social mostrou-se eficaz a partir das experiências de países que tomaram essa medida nas primeiras semanas de confirmação de casos de infecção pelo vírus, a exemplo da Dinamarca, Noruega, Finlândia, Portugal, entre outros. Já países como Itália, Espanha, Estados Unidos e Brasil apresentam um alto índice de disseminação do vírus por relaxamento na medida de isolamento (MACEDO; ORNELAS; BOMFIM, 2020). No Brasil o primeiro caso confirmado foi em 25 de fevereiro, e em 22 de abril já eram contabilizados 45.757 casos e 2.906 óbitos (CAMPOS, 2020).

Importante ressaltar que o Brasil, assim como os Estados Unidos, é um país de grande extensão territorial e demográfica, e as medidas de contingenciamento da pandemia são específicas para cada território, considerando as diferenças regionais, clima, densidade demográfica, alta população do grupo de risco, sistema de saúde e condições econômicas e sanitárias. O isolamento social, além de evitar o contágio de um maior número de pessoas, de modo que a curva de evolução da doença seja achatada ${ }^{1}$, impede também o avanço de uma possível crise sanitária e colapso dos sistemas de saúde, devido ao aumento exponencial das demandas de pacientes por leitos, inclusive em Unidades de Terapia Intensiva.

É notório que a propagação do vírus já provocou crises sanitárias em diversos países no mundo, tais crises serão seguidas de graves problemas econômicos e sociais com consequências demasiadamente profundas, em especial para aqueles países em desenvolvimento, com grandes escalas de desigualdade social e informalidade nas relações de trabalho.

As medidas de higiene requerem a existência de estruturas de saneamento básico e abastecimento de água. Assim como as medidas de isolamento social que geram a redução ou suspensão do rendimento econômico, pressupondo o aumento do gasto social pela necessidade de ampliação da transferência de renda e proteção ao trabalho e emprego, sobretudo nas regiões com elevado índice de trabalho informal. Verificamos que o explicitamente posto na crise sanitária que emerge a partir da pandemia da COVID-9, trata-

\footnotetext{
${ }^{1}$ achatar a curva é um termo usado pelos estudiosos que não significa impedir o contágio, mas protelá-lo de modo que as pessoas serão infectadas num maior espaço de tempo, e, assim, não se acumula grande número de doentes agudizando o sistema de saúde.
}

Temporalis, Brasília (DF), ano 21, n. 41, p. 205-218, jan./jun. 2021. | ISSN 2238-1856 
se de uma crise que tem alicerce, gênese e pano de fundo. Sobre esse aspecto, Gouvêa assinala que:

[...] o vírus, em si, mesmo que entrasse em contato com seres humanos, provavelmente não teria a mesma taxa de letalidade se houvessem sistemas públicos de saúde em condições de contingenciá-lo, sistemas públicos de pesquisa em condições de estudá-lo, sistemas públicos de produção em condições de organizar o acesso aos insumos necessários (GOUVÊA, 2020, p. 21).

A crise se expressa proporcionalmente ao nível de equidade de cada sistema de proteção social vigente no mundo. Dados da Comissão Econômica para América Latina (CEPAL), apontam que os índices de pobreza e extrema pobreza aumentaram em todos os países da região, entre eles o Brasil, entre 2019 e 2020, fator que consequentemente produz a elevação da desigualdade social. Referente aos países que não se preocuparam em construir um sistema de proteção social, universal e equânime, urge mais do que nunca a necessidade de repensar políticas públicas eficazes, a fim de evitar o descaso previsivelmente fatal a sua população em conjunturas pandêmicas ou não.

Desse modo, a reflexão ora apresentada adentra o estudo da proteção social ${ }^{2} \mathrm{com}_{\text {foco na }}$ segurança de renda no PBF, vislumbrando o contexto de crise que desponta com a emergência da pandemia da COVID-19.

\section{A Pandemia da COVID-19 e a eclosão da crise no sistema de proteção social no Brasil.}

No Brasil, lastro da nossa investigação, dentre as iniciativas de garantir o isolamento social da população, em especial para a classe que vive do trabalho $^{3}$, neste contexto, representada por famílias de baixa ou nenhuma renda, em situação de pobreza ou extrema pobreza, ou seja, população em situação de vulnerabilidade social - foi sancionado um Projeto de Renda Básica Emergencial. A lei prevê o auxílio no valor de R\$ 600,00 (seiscentos reais) até $\mathrm{R} \$ \mathbf{1 . 2 0 0 , 0 0}$ (hum mil e duzentos reais) destinado aos trabalhadores desempregados, informais e autônomos, a priori pelo período de três meses.

O público-alvo do auxílio contempla os brasileiros incluídos no Cadúnico, beneficiários ou não do Programa de Transferência de Renda Bolsa Família e demais cidadãos que atendam aos critérios de elegibilidade para receber o benefício e não estejam inscritos no cadastro de programas sociais. Dados do Ministério do Desenvolvimento Social registraram no mês de março/20 no Cadúnico 28.484.729 famílias inscritas, o que corresponde a 75.122.587 pessoas. Destes, 14.274.274 famílias são beneficiárias do Programa Bolsa Família e recebem um valor mensal médio de R\$ 188,16 (BRASIL, 2020a).

\footnotetext{
${ }^{2}$ A concepção de proteção social neste estudo refere-se a uma das funções da política de assistência social, conforme organização do Sistema Único de Assistência Social (SUAS), a qual comtempla a segurança de renda.

3 De acordo com Antunes (2009), classe que vive do trabalho se refere não apenas aos homens e mulheres assalariados que vivem da venda da sua força de trabalho, mas a totalidade da classe trabalhadora na contemporaneidade, composta por: trabalhadores assalariados, rural ou industrial, trabalhadores com contratos de trabalho terceirizados, subcontratados ou temporários, trabalhadores do setor de serviços, telemarketing e call centers, bem como os desempregados e expulsos do mercado de trabalho.
} 


\section{tomporolif cavalcante, almira almeida}

O benefício pecuniário concedido pelo Programa Bolsa Família remete a segurança de renda, um dos mecanismos de segurança afiançado pela política de assistência social no país. A execução do benefício em pecúnia é realizada pela instituição bancária Caixa Econômica Federal (CEF) por meio de cartão magnético. Esse mecanismo de proteção social, por um lado, facilita o acesso e oferece autonomia aos beneficiários no uso do recurso, mas, por outro lado, afirma a relação bancária, configurando-se numa proteção social financeirizada (LAVINAS, 2015).

Quanto ao Projeto de Auxílio Emergencial, é determinado que o valor do benefício seja automaticamente repassado para a população inscrita no Cadúnico; aos beneficiários do Bolsa Família o pagamento deverá obedecer ao calendário do programa, e os demais receberão nas contas já existentes, ou serão abertas contas automaticamente na Caixa Econômica Federal, banco executor do pagamento do auxílio.

Para que o benefício alcançasse a população não inscrita no Cadúnico ou que realizou o cadastro após 2 de abril de 2020, foi disponibilizado um link no site da Caixa e um aplicativo que pode ser baixado no aparelho de telefone celular. A partir de então o benefício passou a ser chamado Auxílio emergencial da Caixa. Nota-se que o relacionamento dos beneficiários da política de assistência social tem como referência o sistema bancário. De um lado, os beneficiários enquanto números, seja pelo Número de Informação Social (NIS) ou Cadastro de Pessoas Físicas (CPF), e, do outro lado, o banco, que aparece como o ente auxiliador no momento da necessidade imediata.

As informações disponibilizadas à população acerca do benefício emergencial não referenciam a política pública de assistência social, vinculada ao Sistema Único de Assistência Social (SUAS) que prevê segurança de renda à população demandatária, seja de forma sistemática ou eventual, referendado na LOAS e ratificado na Portaria $\mathrm{n}^{\circ} 58$, de 15 de abril de 2020, do Ministério da Cidadania/Secretaria Especial do Desenvolvimento Social/Secretaria Nacional de Assistência Social. Tal enquadramento acentua a lógica da financeirização da proteção social (LAVINAS, 2015).

Segundo a Dataprev, 97 milhões de cadastros foram homologados pelo Ministério da Cidadania (informais, Bolsa Família e Cadastro Único), destes, 50,5 milhões recebem até meio salário mínimo por pessoa ou até três salários mínimos de renda mensal total, sendo assim considerados elegíveis para concessão do benefício. A Dataprev esclarece que, no total, 20,5 milhões de CPFs elegíveis pertencem ao grupo 1, composto por Microempreendedores Individuais (MEls), Contribuintes Individuais (Cls) e trabalhadores informais. Já 19,2 milhões de CPFs são do grupo 2, formado pelos inscritos no Cadastro Único e beneficiários do Programa Bolsa Família. E os outros 10,8 milhões de CPFs estão no grupo 3, englobando o Cadúnico, mas não participam do programa de transferência de renda (BRASIL, 2020b).

De acordo com o Banco Mundial o critério adotado para identificar a condição de extrema pobreza é a renda domiciliar mensal per capita inferior a $\mathrm{R} \$ 145,00$ ou $\bigcup \$ S 1,9$ por dia. Para situação de pobreza é definido o valor entre $R \$ 145,00$ e $R \$ 420,00$ (INSTITUTO BRASILEIRO DE GEOGRAFIA E ESTATÍSTICA, 2019). A linha de extrema pobreza e pobreza sobre a qual o governo brasileiro trabalha desde 2010 é de $1 / 4$ salário mínimo e $1 / 2$ salário mínimo. Tendo como referência o valor do salário mínimo dos anos 2000. Os valores atualizados pelo Índice Nacional de Preços ao Consumidor (INPC) até 2010 correspondem aos valores de R\$ 
140,00 e R $\$$ 70,00 respectivamente. Esses valores atualizados pelo Decreto $n^{\circ} 9.396$ de 30 de maio de 2018 , equivale a $\mathrm{R} \$ \mathbf{8 9 , 0 0}$ e 178,00 , representando os índices utilizados para acesso ao Programa Bolsa Família (BRASIL, 2018).

Os dados do grupo 1 apresentados pela Dataprev revelam que os trabalhadores informais somados aos que não alcançaram o acesso ao aplicativo ou não possuem a documentação necessária, estão desconhecidos do sistema de proteção social que prevê ações do governo para melhoria das condições de vida a partir dos programas sociais. Ou seja, tratase de uma população vulnerável, porém oficialmente estranha à responsabilidade do poder público. Tais cidadãos e cidadãs denominados de invisíveis, termo naturalmente empregado, inclusive pelo poder público em canais de comunicação e redes sociais, são seres humanos, providos de capacidades físicas e intelectuais, possuidores de nome e sobrenome, totalmente visíveis e indispensáveis nas suas relações sociais e pessoais em seus territórios de vivência.

A população denominada de 'invisíveis' que emerge a partir do acesso ao auxílio emergencial não se trata de Bot ${ }^{4}$ que alimentam sistemas roboticamente, trata-se de seres humanos, pessoas com nome e sobrenome, são homens, mulheres, mães, pais, filhos, jovens e adultos, que possuem famílias e um lugar de moradia, ainda que não tenham abrigo porque o abrigo é a rua; são pessoas que estabelecem relações sociais, e tais relações necessitam de condições materiais para a sua reprodução. Na busca dessas condições materiais, os ditos invisíveis ganham materialidade, corpo, cor, classe social, gênero, cultura, e tornam-se visíveis e visivelmente destacados, comentados, noticiados, integrando a pauta da grande mídia. Onde estão? nas filas, com o cadastro aprovado e o valor disponível na conta, abstraem a necessidade imediata de saciar a fome, façanha comum ao cotidiano, e encontram-se nas filas quilométricas formadas nas ruas que possuem agências da Caixa em todo território nacional, a partir da liberação do auxílio emergencial. Da liberação dos 600 reais e da alternativa de sobrevivência, e porque não dizer do acesso à proteção social que a população passa a conhecer com a emergência da pandemia da COVID-19.

A visibilidade dada à população que forma a fila pelo auxílio emergencial está repleta de elementos que remetem ao questionamento quanto ao escopo da proteção social, e sua imbricação com a crise sanitária provocada pela pandemia da COVID-19 está estritamente relacionada com as condições de vida das famílias, bem como os seus territórios de vivência, que agora se expressam num lugar comum, a fila do auxílio emergencial da Caixa, a fila dos $\mathrm{R} \$ 600,00$. A fila expressa relações sociais (homens e mulheres de diversos segmentos), regionais e culturais, entre outros elementos externos aos números do aplicativo, pois a fila é composta por gente, e há muita gente na fila.

\footnotetext{
${ }^{4}$ Bot é a versão resumida da palavra de língua inglesa robot. Resumidamente, é uma ferramenta automatizada que executa uma série de funções pré-programadas. Normalmente, está associada à inteligência artificial e busca interagir simulando a forma de pensar humana. Disponível em: https://blog.cedrotech.com/o-que-e-um-bot-entenda-como-funciona. Acesso em: 22 maio 2020.
} 


\section{QUESTÕES POSTAS AO SISTEMA ÚNICO DE ASSISTÊNCIA SOCIAL (SUAS)}

O sistema de proteção social no Brasil está regulamentado no artigo 194 da Constituição Federal de 1988, que preconiza que "A seguridade social compreende um conjunto integrado de ações de iniciativa dos poderes públicos e da sociedade, destinadas a assegurar os direitos relativos à saúde, à previdência e à assistência social [...]" (BRASIL, 1988, p. 105) saúde será gerida pelo Sistema Único de Saúde, regulamentado pela Lei $n^{\circ}$ 8.080/90, que determina as condições para a promoção, proteção e recuperação da saúde, a organização e o funcionamento dos serviços.

A inserção da política de assistência social no tripé da seguridade social alcança o patamar de política pública de Estado, o que significa dizer que se trata de um direito do cidadão e um dever do Estado, executada de forma pública e não contributiva. A Lei Orgânica da Assistência Social (LOAS) provê os mínimos sociais, sendo realizada através de um conjunto integrado de ações de iniciativa pública e da sociedade para garantir o atendimento às necessidades básicas (BRASIL, 1993).

A transferência de renda está pautada na política de assistência social, inserida na função de proteção social básica enquanto segurança de renda, conforme a Norma Operacional Básica do Sistema Único de Assistência Social preconiza:

[...] operada por meio da concessão de auxílios financeiros e da concessão de benefícios continuados, nos termos da lei, para cidadãos não incluídos no sistema contributivo de proteção social, que apresentem vulnerabilidades decorrentes do ciclo de vida e/ou incapacidade para a vida independente e para o trabalho (BRASIL, 2012, p. 17).

A provisão de renda que está inserida no SUAS, “[...] apoio e auxílio: quando sob riscos circunstanciais, exige a oferta de auxílios em bens materiais e em pecúnia, em caráter transitório, denominados de benefícios eventuais para as famílias, seus membros e indivíduos" (BRASIL, 2012, p. 17). No momento, a segurança de renda, convocada pela emergência da crise provocada pela pandemia da COVID-19, formatada como Projeto de Renda Básica - Auxílio Emergencial, aprovado pelo governo, reforça a importância e indispensabilidade da garantia de renda.

Nesse sentido, coloca-se em pauta a discussão da renda básica de cidadania, regulamentada pela Lei $\mathrm{n}^{\circ} 10.835$, de 8 de janeiro de 2004: Art. $1^{\circ}$ - “É instituída, a partir de 2005, a renda básica de cidadania, que se constituirá no direito de todos os brasileiros residentes no País e estrangeiros residentes há pelo menos cinco anos, não importando sua condição socioeconômica, receberem, anualmente, um benefício monetário" (BRASIL, 2004a). A lei da renda básica de cidadania se coloca no reconhecimento da necessidade inadiável da consolidação da transferência de renda no país, e pretendia vigorar com caráter universal e sem exigência de condicionalidades, o que representaria um avanço nas iniciativas do governo com vistas à erradicação da pobreza e minimização das desigualdades sociais.

A propositura da lei da renda básica de cidadania será sequenciada (precisamente um dia depois) pela Lei $n^{\circ} 10.836 / 2004$, que cria o Programa de Transferência Condicionada de Renda Bolsa Família (BRASIL, 2004b). A referida lei imediatamente posterior suprime a perspectiva de assegurar a todos os brasileiros o direito à renda sem imposição de critérios

Temporalis, Brasília (DF), ano 21, n. 41, p. 205-218, jan./jun. 2021. | ISSN 2238-1856 
de elegibilidade dados pelas condicionalidades de inserção requeridas pelo programa. Nesse sentido, a transferência de renda proposta e implementada no país virá desmontar o caráter universal proposto pela lei da renda básica de cidadania.

A evolução da transferência de renda até o PBF tem início quando o Programa Nacional de Renda Mínima é substituído pelo Programa Nacional de Bolsa Escola (PNBE/2001), vinculado ao Ministério da Educação (MEC), que contemplava famílias com crianças de 6 a 15 anos, com renda familiar per capita inferior a meio salário-mínimo. O benefício recebido era de $\mathrm{R} \$ 15,00$ por criança em idade escolar, admitindo o teto de $\mathrm{R} \$ 45,00$ por família. Esse programa já apontava o critério de condicionalidade, acesso e permanência dos beneficiários, crianças, na escola. Paralelo ao Bolsa Escola foi criado o Programa Bolsa Alimentação (2001), tendo como alvo a população materno-infantil, e concedido a famílias compostas por gestantes, nutrizes e crianças na faixa etária de até 6 anos. 0 teto da renda familiar era igual ao teto do Bolsa Escola. Como condicionalidades, o programa apontava os cuidados com a saúde das crianças, gestantes e nutrizes. O sucesso desses programas e a abrangência superior a mais de um milhão de pessoas resultaram na ampliação da transferência de renda no país, a saber: Agente Jovem, e Bolsa Renda.

Nesse contexto, apesar da mudança de gestão em 2003, a implementação da transferência de renda, enquanto política pública de combate à pobreza, ganha maiores proporções a partir da criação do Ministério Extraordinário da Segurança Alimentar e Combate à Fome (MESA), com foco determinante no combate à fome no país. A iniciativa central dessa pasta foi a criação do Programa Nacional de Acesso à Alimentação (Cartão Alimentação), porém esse programa, além do aspecto condicional, também contemplava território de abrangência (região do semiárido, comunidades indígenas e quilombolas) e o prazo era de dezoito meses, iniciando com seis e mais duas prorrogações. Importante ressaltar que o caráter condicional da transferência de renda atrelado à saúde e à educação objetivava romper com a transmissão intergeracional da pobreza, por meio do aumento do capital humano das futuras gerações (BRITTO, 2010).

O Bolsa Família, após dezesseis anos de existência, consolida, em termos quantitativos, uma cobertura jamais alcançada, e, em termos qualitativos, uma relevância imensurável na vida dos beneficiários ${ }^{5}$, conforme apontam as inúmeras pesquisas que se debruçam sobre a temática. Contudo, a conjuntura da pandemia da COVID-19 evidencia a insuficiência do sistema de proteção social no que se refere à segurança de renda.

O número de acessos ao cadastro materializado nas filas revela que o quantitativo de 14.274.274 famílias alcançadas pelo programa em abril de 2020, número que representa cerca de $50 \%$ das famílias inscritas no Cadúnico, sequer representa a real necessidade de cobertura expressa nas filas do auxílio emergencial da Caixa concedido extraordinariamente pela ocasião da pandemia. O que significa dizer que há uma grande parcela da população não incluída nos programas sociais, população necessitada, classificada como microempreendedor individual, contribuinte individual ou trabalhador informal, especialmente este último, que está desprotegido. O quadro denuncia a

\footnotetext{
${ }^{5}$ Consultar: REGO e PINZANI, (2013) e LAVINAS (2012).
} 
negligência do Estado e ineficácia do sistema de proteção social. Constata-se que o CadÚnico não abrangeu a população prioritária composta pelos mais vulneráveis, ou seja, não logrou seu objetivo central.

Assinalamos que uma crise sanitária se expande na medida em que as políticas públicas consumam a inoperância ao seu enfrentamento, no caso, a desproteção dos cidadãos e cidadãs frente ao fenômeno da pandemia, propiciando a dimensão da crise no Brasil. A pandemia provocada pela COVID-19 revelou desigualdades sociais e territoriais visto que impactou sobremaneira o sistema de proteção social do país e contestou a segurança de renda afiançada na política de assistência social conforme modelo de transferência de renda condicionado no Programa Bolsa Família.

A Norma Operacional Básica do SUAS citada anteriormente, instrumento que disciplina a política de assistência social no país, anuncia a adoção de um modelo de desenvolvimento econômico atrelado ao desenvolvimento social e à atenção às populações em situação de pobreza, vulnerabilidade e risco pessoal e social (BRASIL, 2012). Esse modelo, segundo Lavinas (2015) visa "[...] assegurar mínimos monetários e provisão de serviços para reduzir a vulnerabilidade das famílias pobres" (LAVINAS, 2015, p. 6).

Estudo recente que avaliou a dimensão do trabalho no Brasil aponta que: “[...] os dados evidenciam que a desocupação no atual período se ampliou fortemente, com a taxa média anual saindo de $6,8 \%$, em 2014, e atingindo 11,9\%, em 2019, o que corresponde a 12,6 milhões de pessoas e representa um dos maiores valores da taxa e do contingente de desocupados dos últimos anos" (CASTRO, 2020, p. 58). Tais resultados requisitam a intervenção do sistema de proteção social, priorizando a garantia de acesso à renda ${ }^{6}$. Outrossim, refletir sobre a ampliação do escopo da proteção social, incute a ressignificação do SUAS de modo que a população ora excluída se torne partícipe das seguranças afiançadas na e póspandemia.

A crise sanitária provocada pela pandemia e seus rebatimentos na proteção social descortinam a desproteção do SUAS, no que se refere a segurança renda, que se acentua prioritariamente na manifestação da população não alcançada pela cobertura, ao mesmo tempo que viola a normativa da política de assistência social que prevê garantias de proteção social para quem dela necessitar.

Assinalamos ser o PBF um mecanismo substancial no combate à pobreza no país, com cobertura superior a 14 milhões de famílias, representando em média 56 milhões de pessoas beneficiadas, porém os números significam o alcance de apenas $50 \%$ da população inscrita no Cadúnico, voltado para os pobres e extremamente pobres, agora manifestados na emergência da pandemia da COVID-19.

A iniciativa de analisar a transferência de renda do PBF como fator de proteção social permite evidenciar aspectos relevantes observados diretamente na vida do beneficiário,

\footnotetext{
${ }^{6}$ Advertimos que renda aqui, constitui-se como um componente da proteção social afiançada pelo SUAS, conforme preconiza a NOBSUAS/2012. Esclarecendo nosso entendimento de que a proteção social de forma integral, deverá contemplar prioritariamente as políticas inseridas no Sistema e Seguridade Social (Saúde, Previdência e Assistência Social), bem como os direitos sociais contidos no Artigo $6^{\circ}$ da Constituição Federal de 1988, tais como: direto à alimentação, ao trabalho, à moradia, ao transporte, ao lazer, à segurança, etc.
}

Temporalis, Brasília (DF), ano 21, n. 41, p. 205-218, jan./jun. 2021. | ISSN 2238-1856 
que numa avaliação preliminar permite retirá-lo da situação de extrema pobreza, proteção afiançada pela segurança de renda no âmbito da política de assistência social, bem como no contexto das demais políticas públicas que acontecem por meio do cumprimento das condicionalidades, refletindo diretamente no aumento da demanda dos serviços ofertados pelas políticas de saúde (vacinação, pré-natal, saúde do lactente) e educação (acesso e permanência na escola) ${ }^{7}$.

A transferência de renda requer condicionalidades diretamente vinculadas às políticas de saúde, educação e assistência social ${ }^{8}$. De acordo com o objetivo do programa, vincular o benefício à inserção da população atendida nas políticas sociais, corresponde à função para além da transferência de renda, que já garante o alívio imediato da fome, mas também visa superar a condição de vulnerabilidade social. Entretanto é necessário verificar como se dá a oferta da proteção social, por meio dos serviços, nos territórios e refletir acerca das condições de cumprimento da população.

\section{CONSIDERAÇÕES FINAIS}

O desafio posto ao SUAS na atualidade é apresentar novas ferramentas de análise, ou aprimorar as existentes, de conhecidos fenômenos sociais revestidos das circunstâncias pandêmicas, que possibilitem propor ações na gestão da política pública de assistência social, na construção de caminhos, estratégias e técnicas de produção e socialização do conhecimento, que possam contribuir para um novo modus operandi do SUAS a partir do mecanismo da transferência de renda. O que implica, sobretudo, operar instrumentos que revelem uma (re)leitura das condições de vida dos lugares e de suas complexas configurações de exclusão/inclusão social (CONSERVA, 2014).

A problematização em torno da cobertura incipiente do PBF, posto a ausência de uma renda básica de cidadania, agrava as expressões da questão social na população desassistida pelo SUAS na ocorrência da pandemia, e os desdobramentos que se anunciam levantam questões postas ao SUAS: Em que consiste a materialidade da proteção social via transferência de renda, frente à capacidade irrelevante de cobertura? Em que medida há capacidade de proteção às famílias beneficiárias? O auxílio emergencial prenuncia a inevitável ampliação e universalização da cobertura da transferência de renda?

\footnotetext{
${ }^{7}$ As condicionalidades provocam desacordo entre os autores. Por exemplo, Lavinas (2015) alerta que o não cumprimento de condicionalidades pode levar a suspensão do benefício, ou seja, viola o direito à transferência de renda. Sabemos que não é possível cumpri-las quando os serviços da política de saúde e educação não estão acessíveis para todos, o que independe da iniciativa do beneficiário.

${ }^{8}$ Periodicamente, o Ministério da Cidadania gera o público para acompanhamento (PA) das condicionalidades, ou seja, para a área de educação, uma base com informações das crianças e adolescentes que deverão ter a frequência escolar verificada, e para a área da saúde, uma base com informações das crianças menores de 7 anos que deverão ter o calendário vacinal, o peso e a altura acompanhados, além de dados das mulheres para identificação das gestantes e acompanhamento da realização do pré-natal. 0 público com perfil para acompanhamento das condicionalidades é gerado pelo Ministério da Cidadania com base na Folha de Pagamentos do PBF e nas informações advindas do Cadastro Único, conforme Guia para Acompanhamento das Condicionalidades do Bolsa Família (BRASIL, 2020c).
} 
Asseveramos que responder de forma consistente às questões registradas carece aprofundar o debate estabelecido nessa reflexão. Entretanto, ousamos apontar alguns pressupostos: quanto a materialidade da proteção, há urgência na elevação da cobertura para alcançar a população não incluída no Cadúnico, tendo em vista que o cenário pandêmico trouxe à tona os reclames desta população, antes apenas vista e/ou discutida enquanto dados de pesquisa, agora compulsoriamente visibilizada, trata-se de gente de fato, vida real, necessitada de mecanismos mínimos de proteção social, a exemplo da transferência de renda do SUAS.

Quanto à capacidade de proteção aos beneficiários, inferimos que não cumpre a função do SUAS no sentido de provisão de recursos necessários à sobrevivência dos cidadãos, preconizados na LOAS, tendo em vista que o valor do benefício não obedece a atualização do corte de renda para pobreza e extrema pobreza de acordo com os padrões determinados pelas agências internacionais, a exemplo do Banco Mundial. Ademais, como já apontamos não cumpre a prerrogativa de atender a quem dela necessita (BRASIL, 1993).

Finalmente, a exorbitante demanda pelo auxílio emergencial imputa ao Estado a responsabilidade também com a população não beneficiária, não inclusa no Cadúnico, a qual emerge enquanto cidadãos, e, por conseguinte, sujeito de direitos. Portanto, cabe ao SUAS redirecionar a competência de assegurar proteção social via transferência de renda na perspectiva do direito, ou seja, significa corresponder diligentemente aos seus fundamentos constitutivos, precipuamente o princípio da universalidade.

\section{REFERÊNCIAS}

ANTUNES, Ricardo. Os sentidos do trabalho: ensaio sobre a afirmação e a negação do trabalho. São Paulo: Boitempo, 2009.

BRASIL. Constituição Federal (1988). Constituição da República Federativa do Brasil. Disponível em: http://www.planalto.gov.br/ccivil_03/constituicao/constituicao.htm. Acesso em: 20 maio 2020.

BRASIL. Lei n ${ }^{\circ}$ 10.835, de 8 de janeiro de 2004. Institui a renda básica de cidadania. Brasília (DF), 2004a. Disponível em: http://www.planalto.gov.br. Acesso em: 30 maio 2020.

BRASIL. Lei $\mathbf{n}^{\circ} \mathbf{1 0 . 8 3 6}$, de 9 de janeiro de 2004. Cria o Programa Bolsa Família. Brasília (DF), 2004b. Disponível em: http://www.planalto.gov.br. Acesso em: 30 maio 2020.

BRASIL. Ministério do Desenvolvimento Social e Combate à Fome. Secretaria Nacional de Assistência Social. Norma Operacional Básica do Sistema Único de Assistência Social SUAS - 2012. NOB/SUAS/2012. Brasília (DF): MDS, 2012.

BRASIL. Ministério da Cidadania. Secretaria de Avaliação e Gestão da Informação. Relatório de Informações Sociais. Relatório de Programas e Ações do Ministério da Cidadania, 2020a. Disponível em: https://aplicacoes.mds.gov.br/sagi/RIv3/geral/index.php Acesso em: 2 mar. 2020.

BRASIL. Decreto 9.396, de 30 de maio de 2018. Altera o Decreto $n^{\circ}$ 5.209, de 17 de setembro de 2004, e o Decreto $n^{\circ}$ 7.492, de 2 de junho de 2011. Brasília (DF), Disponível

Temporalis, Brasília (DF), ano 21, n. 41, p. 205-218, jan./jun. 2021. | ISSN 2238-1856 
em: http://www.planalto.gov.br/ccivil_03/_Ato2015-2018/2018/Decreto/D9396.htm. Acesso em: 13 abr. 2020.

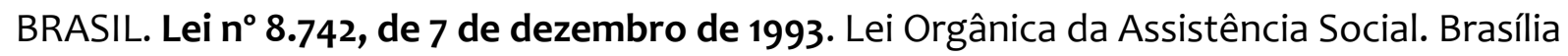
(DF), 1993. Disponível em: http://www.planalto.gov.br. Acesso em: 30 maio 2020.

BRASIL. Ministério da Cidadania. Programa Bolsa Família. Brasília (DF), 2018. Disponível em: https://www.gov.br/cidadania/pt-br. Acesso em: 20 de abril de 2020.

BRASIL. Empresa de Tecnologia e Informação da Previdência (DATAPREV). Brasília (DF), 2020b. Disponível em: https://portal2.dataprev.gov.br/COVID-19. Acesso: 8 jun. 2020.

BRASIL. Ministério da Cidadania. Secretaria Nacional de Renda e Cidadania. Guia para Acompanhamento das Condicionalidades do Programa Bolsa Família. Brasília (DF), 2020C. Brasília (DF), 2020.

BRITTO, Tatiana; SOARES, Fabio Veras. Bolsa Família e Renda Básica de Cidadania-um passo em falso? Brasília (DF): Senado Federal, 2010.

CAMPOS, D.S. O Cadastro Único na pandemia do Coronavírus: panorama da (des)proteção social. In: MOREIRA, Elaine; GOUVEIA, Raquel et al. Em Tempos de Pandemia: propostas para defesa da vida e dos Direitos Sociais. Rio de Janeiro: UFRJ, Centro de Filosofia e Ciências Humanas, Escola de Serviço Social, 2020.

CASTRO, J. A. Bem-estar social brasileiro pré-COVID-19: graves debilidades propícias a tragédias. In: CASTRO, J. A.; SENO, D.D.; POCHMANN, M. Capitalismo e a COVID-19. São Paulo, 2020. Disponível em: http://abet-trabalho.org.br/wpcontent/uploads/2020/05/LIVRO.CapitalismoxCovid19.pdf. Acesso em: 4 maio 2020.

COMISSIÓN ECONÓMICA PARA AMÉRICA LATINA Y EL CARIBEI (CEPAL). Informe Especial sobre la evolución y los efectos de la pandemia del COVID-19 en América Latina y el Caribe. Edição n. 3, Maio 2020. Disponível em: www.cepal.org. Acesso em: 20 mai. 2020.

CONSERVA, M.S. Relatório Técnico da Pesquisa Proteção Social da Família. João Pessoa: Núcleo de Estudos e Pesquisas em Políticas Sociais, Casadinho PROCAD, 2014.

DICIONÁRIO ONLINE DE PORTUGUÊS 2020. Disponível em: https://www.dicio.com.br. Acesso em: 25 abr. 2020.

FREITAS, A.R.R.; NAPIMOGA, M.; DONALISIO, M.R. Análise da gravidade da pandemia de COVID-19. Revista Epidemiologia e Serviços de Saúde. Brasília, v. 29, n. 02, p. 1-5, abr. 2020.

GOUVÊA, M.M. A culpa da crise não é do vírus. In: MOREIRA, Elaine; GOUVEIA, Raquel et al. Em Tempos de Pandemia: propostas para defesa da vida e dos Direitos Sociais. Rio de Janeiro: UFRJ, Centro de Filosofia e Ciências Humanas, Escola de Serviço Social, 2020. 
INSTITUTO BRASILEIRO DE GEOGRAFIA E ESTATÍSTICA. Síntese de Indicadores Sociais. Brasília (DF), 2019. Disponível em: https://agenciadenoticias.ibge.gov.br. Acesso em: 2 maio 2020.

LAVINAS, Lena. A financeirização da política social: o caso brasileiro. Forthcoming at Politika. Rio de Janeiro: Fundação João Mangabeira em colaboração com HumboldtViadrina Governance Platform, 2015. p.35-51.

LAVINAS, Lena; COBO, Barbara; VEIGA, Alinne. Bolsa Família: impacto das transferências de renda sobre a autonomia das mulheres pobres e as relações de gênero. Revista Latino americana de Población, 6.10 (2012): 32

MACEDO, Yuri Miguel; ORNELLAS, Joaquim Lemos; BOMFIM, Helder Freitas do. COVID 19 NO BRASIL: o que se espera para população subalternizada? Revista Encantar -

Educação, Cultura e Sociedade, [S.I.], v. 2, p. 01-10, jan. 2020. Disponível em: http://www.revistas.uneb.br/index.php/encantar/article/view/8189. Acesso em: 2 abr. 2020.

ORGANIZAÇÃO MUNDIAL DE SAÚDE (OMS). Disponível em: https://www.who.int/eportuguese/countries/bra/pt/. Acesso em: 17 abr. 2020.

PASSOS, R.G. A carne mais barata do mercado é a carne negra: saúde da população negra em tempos de COVID-19. In: MOREIRA, Elaine; GOUVEIA, Raquel et all. Em Tempos de Pandemia: propostas para defesa da vida e dos Direitos Sociais. Rio de Janeiro: UFRJ, Centro de Filosofia e Ciências Humanas, Escola de Serviço Social, 2020.

REGO, Walquiria Leão; PINZANI, Alessandro. Vozes do Bolsa Família: autonomia, dinheiro e cidadania. 2 ed. São Paulo: Unesp, 2014.

\footnotetext{
Almira Almeida Cavalcante

Doutoranda em Estudos Urbanos e Regionais - Gestão de Políticas Públicas - no Programa de Pós-Graduação em Estudos Urbanos e Regionais do Departamento de Políticas Públicas da Universidade Federal do Rio Grande do Norte (UFRN). Mestra em Serviço Social pelo Programa de Pós-Graduação em Serviço Social da Universidade Federal da Paraíba (UFPB/2011). Especialista em Serviço Social pela Instituto Universitário de Lisboa/ Portugal (ISCTE/2016). Especialista em Saúde da Família pela Universidade Integrada de Patos (FIP/2006). Graduada em Serviço Social pela Universidade Federal da Paraíba (UFPB/2004). Assistente Social da Secretaria de Educação do Município de João Pessoa (PMJP). Professora Substituta do Departamento de Serviço Social da Universidade Federal da Paraíba (março/2019 - Abril/2021). Pesquisadora do Núcleo de Estudos e Pesquisas sobre Crianças e Adolescentes e Famílias (GEPAC/UFPB), supervisora de campo da Pesquisa: Violação de Direitos e Vulnerabilidade Social de crianças e adolescentes e famílias no Estado da Paraíba (2016/2017). Pesquisadora do Núcleo de Estudos e Pesquisas em Políticas Públicas e Sociais (NEPPS/UFPB), atuando no Projeto em andamento Plataforma COVID-19 - Relações entre Saúde, Território e Proteção Social em Tempos se Crise Sócio-Sanitária. Pesquisadora colaboradora do Projeto de Pesquisa (PIBIC): Em Tempos da Crise da COVID-19: participação e capacidade protetiva das famílias de pescadores artesanais da REXEX Acaú/Goiana na Paraíba.
} 